\title{
Structural design of three-axis turntable for a flight simulation Liu Qucheng ${ }^{1, a}$, Hou Zhenhua ${ }^{2, b}$, Zhang Huij,c, Deng Qingdong ${ }^{4, d}$ and Zhu \\ Jilin University, Changchun 130025, China \\ ${ }^{*}$ Corresponding author \\ *E-mail: zhuxy@jlu.edu.cn
}

Key words: three-axis turntable, structural design, mechanical calculation, measurement and testing, static analysis, modal analysis, harmonic response analysis.

\begin{abstract}
In this paper, the structural design of the three-axis turntable mechanical platform of flight simulation is mainly carried out. The structure and driving mode of the simulation turntable are selected. By reading the literature, the selection of the frame material of the shaft and the selection of standard parts such as bearings and motors are made. The main mechanical loads of the internal structure of the three-axis turntable, the middle ring structure and the outer ring structure are calculated to determine the type of the measuring and testing device.The finite element model of the simulation turntable was established, and its static analysis and structural dynamics analysis.
\end{abstract}

\section{Introduction}

As one of the test turntables, the flight simulation three-axis turntable can control Inner ring structure, middle structure and outer ring structure of the simulation turntable by PC. The structure of a ring driven by a motor or hydraulic motor rotates according to a predetermined algorithm, so that simulated turntable fixed target simulator can obtain similar or the same motion attitude as in the actual flight of the aircraft and the target carrier that hold the expected angular velocity, rotation angle, or angular acceleration can be protected. [1-3]. In order to get the simulation results of the motion and attitude of the real aircraft,simulation turntable should be designed to ensure that its mechanical structure has good static and dynamic performance.In the control and analysis functions require better friction compensation methods and control programs [3].

The detection device has experienced the process from simple fretting switch to later electric sensing system to higher precision grating sensor and inertial sensor. The choice of bearing from the initial ordinary ball bearings into precision tapered roller bearings and then to the smaller friction coefficient flotation bearings. The simulation turntable can be controlled in a variety of modes. And the adaptive control method can compensate the error of the turntable itself, and can better simulate the flight attitude of the real aircraft. Because of the great role of simulation turntable in military and national defense industry, the technology has been restricted and blocked by foreign countries. The development of the first simulation turntable in our country was successful in 1965, which is later than that in the western developed countries, but it is developing rapidly and the gap with foreign countries is narrowing. It has been possible to develop a single-axis turntable, a two-axis turntable, a three-axis turntable or even a five-axis turntable.Nowadays, the leading research units in the field of simulation state in China include Changchun Institute of Optics Fine Mehcanics and Physics, Chinese Academy of Sciences, Institute of Precision Machinery of the first Institute of Aerospace, Harbin Institute of Technology Northwestern Polytechnical University and Nanjing University of Aeronautics and Astronautics[4-6].

Flight simulation three-axis turntable design process is actually based on the need to design the flight simulation and the three-axis turntable is expected to reach the parameters and indicators[7]. So it is for the design of the main structure, drive, measurement feedback system and control system design. 


\section{Structure design of simulation turntable}

Flight simulation three-axis turntable includes three parts which include mechanical structure , PC , and electric control cabinet . Its main function is to simulate a variety of flight movements, including the simulation of aircraft flight, missile or satellite and other aircraft to imitate the pitch, rotation and roll.

\subsection{Flight Simulation Three-axis turntable technical indicators}

Structural indexes, static performance indexes and dynamic performance indexes are the three main technical indexes of the three-axis turntable of flight simulation. Only when the three indexes meet the corresponding technical parameters can the flight simulation three-axis turntable be designed to meet the static performance, reliability, fast response and structural accuracy.

Table 1 flight simulation three-axis turntable technical indicators

\begin{tabular}{|c|c|c|c|}
\hline parameter name & $\begin{array}{l}\text { Inner shaft } \\
\text { (roll) }\end{array}$ & $\begin{array}{l}\text { Center } \\
\text { (pitch) }\end{array}$ & $\begin{array}{r}\text { Outer } \\
\text { (rotation) }\end{array}$ \\
\hline Range of motion $\left(^{\circ}\right)$ & \pm 360 & \pm 360 & \pm 360 \\
\hline Position accuracy $\left(^{\circ}\right)$ & \pm 0.001 & \pm 0.001 & \pm 0.001 \\
\hline Repeat accuracy $\left(^{\circ}\right)$ & \pm 0.001 & \pm 0.001 & \pm 0.001 \\
\hline $\begin{array}{l}\text { Maximum angular } \\
\text { velocity }\left({ }^{\circ} / \mathrm{S}\right)\end{array}$ & 3600 & 1800 & 1800 \\
\hline $\begin{array}{l}\text { Minimum angular velocity } \\
\left({ }^{\circ} / \mathrm{S}\right)\end{array}$ & 0.005 & 0.005 & 0.005 \\
\hline $\begin{array}{l}\text { Maximum acceleration } \\
(\circ / \mathrm{S})\end{array}$ & 3000 & 2000 & 1000 \\
\hline $\begin{array}{l}\text { Double ten band width } \\
(\mathrm{Hz})\end{array}$ & 10 & 8 & 6 \\
\hline Table beat (mm) & & 0.05 & \\
\hline Load weight (kg) & & 40 & \\
\hline Load size (mm) & & $300 * 300 * 200$ & \\
\hline Computer system & & General or IPC & \\
\hline Ambient temperature $\left({ }^{\circ} \mathrm{C}\right)$ & & $20 \pm 5$ & \\
\hline
\end{tabular}

\subsection{Structure form}

There are two main types of simulation turntable structure, including vertical turntable and horizontal turntable. As shown in Fig 1, the three axis frame of horizontal simulation turntable are all O-shaped. This structure is good for improving the inherent frequency of the frame. The horizontal simulation turntable has a large base, and the two ends are used for fixing the driving motor or hydraulic motor. Vertical simulation turntable is not the same ,as shown in Fig 2,the inner ring structure frame and the middle ring structure frame are O-type structures. The outer ring structure is of the U-shaped structure and the base is usually hollow cast from cast iron. The outer ring structure of the drive motor installed in the middle of the base .According to the structure characteristics of the turntable system and the design requirements of the simulation turntable, this paper adopts the structure of the vertical simulation turntable .

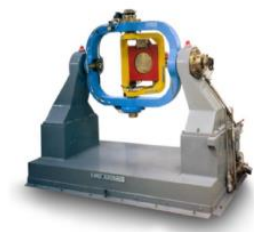

Fig 1 Horizontal Simulation Turntable Structure (left)

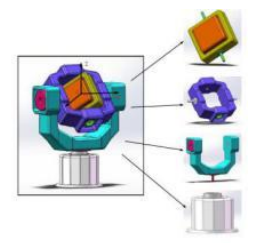

Fig 2 Vertical Simulation Turntable Structure (right)

\subsection{Material selection of simulation turntable}

For a device, the choice of materials have a great impact on its structural rigidity, resonant frequency and quality characteristics. The following article on the study of several typical materials commonly 
used in various performance comparison [8]. By considering equipment costs, mechanical properties and Processing performance. The framework of the inner ring, the middle ring and the outer ring structure of the final choice of cast aluminum ZL101. The base has been chosen for the gray cast iron HT300 because it guarantees good machinability with the required mechanical properties. This material is more uniform in indifferent cross-section performance, and gray cast iron has a good damping, low cost, easy processing and so on.

\subsection{Drive mode}

By analyzing the design requirements and design indexes and considering the possible limitations of the vertical simulation turntable in terms of installation space and installation method, the simulation turntable in this paper uses a direct drive motor.By comparing various types of motor performance parameters and their advantages and disadvantages, the final drive motor adopts brushless DC torque motor.

\section{Bearing selection of simulation turntable}

Bearing is one of the key components of flight simulation three-axis turntable.Bearing accuracy, stiffness, friction torque will be straight affect the three-axis turntable dynamic and static characteristics [9]. Through the movement and force analysis of the shaft of three-axis rotary table structure, the connecting bearing between the inner ring structure and the middle ring structure should select the bearing which can bear the axial force and the radial force. This article is selected two sets of SKF company's double row angular contact ball bearings 3205A. After calculating the load and comparing it with SKF double row angular contact ball bearing samples, this paper uses two set of 3207A double row angular contact ball bearings. For the base and the outer ring connection part, this selection of a set of SKF double row deep groove ball bearings 4208ATN9 and a set of SKF's oneway thrust ball bearings 51224 . Table 2 shows the detailed parameters of the selected bearings.

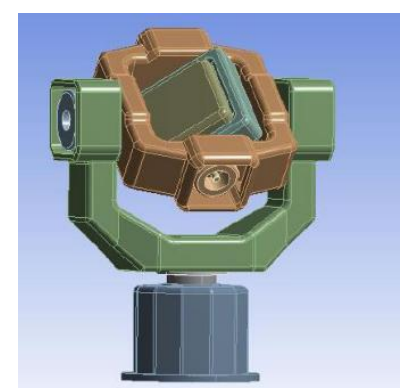

Fig 3 Flight Simulation Three-axis turntable simplified diagram

Table 2 Simulation Turntable bearing detailed parameters

\begin{tabular}{|c|c|c|c|c|c|c|c|c|c|}
\hline \multirow[t]{2}{*}{ model } & \multicolumn{3}{|c|}{ basic size } & \multicolumn{2}{|c|}{$\begin{array}{l}\text { basic load } \\
\text { rating }\end{array}$} & $\begin{array}{l}\text { Fatigue } \\
\text { load } \\
\text { Limit }\end{array}$ & $\begin{array}{l}\text { rated } \\
\text { Rotating } \\
\text { speed }\end{array}$ & $\begin{array}{l}\text { limit } \\
\text { Rotating } \\
\text { speed }\end{array}$ & $\overline{\text { quality }}$ \\
\hline & $\begin{array}{l}\mathrm{d} \\
\mathrm{mm}\end{array}$ & $\begin{array}{l}\mathrm{D} \\
\mathrm{mm}\end{array}$ & $\begin{array}{l}\mathrm{H} \\
\mathrm{mm}\end{array}$ & $\begin{array}{l}\mathrm{C} \\
\mathrm{kN}\end{array}$ & $\begin{array}{l}\mathrm{C}_{0} \\
\mathrm{kN}\end{array}$ & $\begin{array}{l}\mathrm{Pu} \\
\mathrm{kN}\end{array}$ & $\mathrm{r} / \mathrm{min}$ & $\mathrm{r} / \mathrm{min}$ & $\mathrm{kg}$ \\
\hline $3205 \mathrm{~A}$ & 25 & 52 & 20.6 & 21.6 & 14.3 & 0.6 & 12000 & 12000 & 0.18 \\
\hline $3207 \mathrm{~A}$ & 35 & 72 & 27 & 40 & 28 & 1.18 & 9000 & 9000 & 0.44 \\
\hline 51224 & 120 & 170 & 39 & 127 & 390 & 11.8 & 1600 & 2200 & 2.65 \\
\hline 4208ATN9 & 40 & 80 & 23 & 37.1 & 32.5 & 1.37 & 13000 & 7000 & 0.5 \\
\hline
\end{tabular}

\section{Turntable main calculation load and drive motor calculation}

In the process of designing the three-axis turntable, the basic physical properties such as moment of inertia and mass of each collar of the simulation turret are calculated first. Then the specific parameters 
such as the angular velocity and angular acceleration of each collar structure are required to be analyzed .Calculate the motor torque, power etc.And select the appropriate motor according to the specifications of the motor finally.

\subsection{Calculation of inner ring structure and selection of drive motor}

The moment of inertia of the inner ring frame relative to its axis of rotation consists of two parts, the moment of inertia of the inner frame and the load. As shown in Fig 3, in theory, the load needs to be installed in the middle of the rectangular frame of the inner ring structure. This not only minimizes the moment of inertia of the load on the rotating shafts of the system, but also reduces errors due to load eccentricity. However, it is impossible for the actual work load and the centroid of the testing device to be on the roll axis. Therefore, this paper appropriately enlarges the moment of inertia of the inner ring and the load structure.

The load described here is a rectangular with a size of $300 * 300 * 200$ and a mass of $40 \mathrm{~kg}$. Assuming uniform density, the calculated value of the moment of inertia of the load with respect to the roll axis is given by the moment of inertia formula of the rectangular (1) .

$$
\begin{aligned}
& J=\iiint_{\Omega}\left(x^{2}+y^{2}\right) \rho(x, y, z) d x d y d z \\
& J=\frac{1}{12} m\left(w^{2}+d^{2}\right)
\end{aligned}
$$

Among them: J: moment of inertia m: mass of the cuboid w: width of the cuboid d: thickness of the rectangular.

$$
J=\frac{1}{12} \times 40\left(0.3^{2}+0.2^{2}\right)=0.433 \mathrm{~kg} \cdot \mathrm{m}^{2}
$$

The inner ring frame is a rectangular hollow frame cast from cast aluminum ZL101 to ensure that the shaft of the inner ring structure has sufficient rigidity to withstand loads and to transmit movement and power. The shaft of the inner ring structure adopts the green part at the upper and lower ends of the inner ring frame as shown in Fig. 4.Its structure is made of 45 steel shaft and cast aluminum ZL101 frame solid together. Fig 4 is a 3D drawing of the inner ring structure drawn by SOLIDWORKS 3D drawing software. The mass characteristics of the inner ring structure can be calculated in the 3D drawing software, and the moment of inertia of the inner ring structure with respect to the rotation axis of the inner ring structure is $\mathrm{J} 1=0.331 \mathrm{~kg} \cdot \mathrm{m}^{2}$.

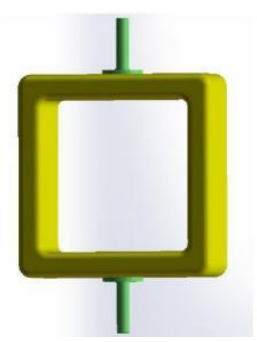

Fig 4 Inner ring structure diagram

The total moment of inertia of the simulation turntable inner frame structure relative to the roll axis is:

$$
J_{\text {inner }}=J_{\text {minus }}+J_{1}=0.764 \mathrm{~kg} \cdot \mathrm{m}^{2}
$$

By considering the factors such as lubrication, friction and other factors between the bearings of the inner frame shaft and other mechanisms, the actual value of the moment of inertia of the driving motor with the inner frame structure should be taken as 1.5 times the calculated value.that is

$$
J_{x}=1.5 \times J_{\text {inner }}=1.146 \mathrm{~kg} \cdot \mathrm{m}^{2} .
$$

From the rotation theorem, it can be seen that when the inner frame structure rotates around the fixed axis the motor shaft load torque is: 


$$
T_{x m}=\frac{J_{x} \varepsilon_{x m}}{\eta}=\frac{1.148 \times 3600}{0.9 \times 180}=25.5 \mathrm{~kg} \cdot \mathrm{m}^{2}
$$

The inner frame structure driven motor selected in this paper is the J160LYX05R permanent magnet DC torque motor of Chengdu Precision Motor Factory. Its maximum output torque is $31 \mathrm{~N} \cdot \mathrm{m}$, the peak power is $0.528 \mathrm{KW}$, the mass is $4.37 \mathrm{~kg}$, to meet the requirements.

\subsection{Central and outer ring structure of the calculation of load and drive motor selection}

Similarly, the calculation of the central structure of the load and the choice of drive motor.The motor selected in this paper, the output torque is slightly larger than the calculated torque value.The middle frame structure drive motor selection Chengdu Precision Motor Factory J180LYX09 Permanent Magnet DC force Moment motor, the

maximum output torque of $80 \mathrm{~N} \cdot \mathrm{m}$, a mass of $12.42 \mathrm{~kg}$. Finally, the calculation of the external structure of the load and the choice of drive motor. The frame structure of the drive motor selection Chengdu Precision Motor Factory Permanent Magnet DC torque motor J285LYX08, the maximum output torque of $300 \mathrm{~N} \cdot \mathrm{m}$, a mass of $23.4 \mathrm{~kg}$.

\section{Measuring and testing device}

By referring to the data and the research on the design requirements of the simulation turntable, this simulation turntable selects KUEBLERCHINA 5888 Multi-turn absolute encoder and ADIS16355 MEMS inertial sensor to simulate the speed and acceleration with the location of detection.

\section{Finite element analysis results}

\section{1 static analysis}

Based on the static characteristic of simulation turntable, Successively, SOLIDWORKS 3D modeling, ANSYS Workbench (AWB) finite element model transformation (simplification), finite element model material setting, joint surface processing, mesh division (Fig5), addition of constraints and loads were performed on the simulation turntable. Static analysis of the simulation turntable has been simulated turntable static deformation, strain, stress and other mechanical properties. As for the static analysis, considering the inner structure and middle ring structure in the horizontal position, vertical position and arbitrary position may be subjected to different situations of three cases were analyzed.As shown in Fig 6 and Fig 7 , the inner ring and the middle ring structure in the vertical position of the whole deformation, equivalent stress and equivalent plastic strain nephogram.

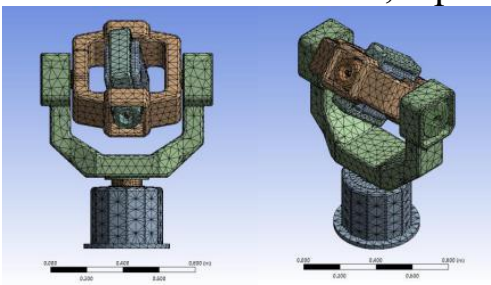

Fig 5. simulation turntable finite element mesh model (left)

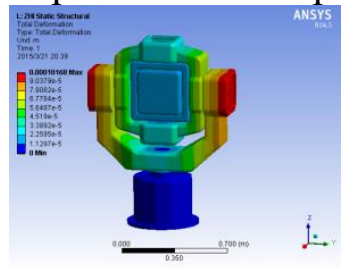

Fig. 6 Static deformation when the inner frame structure and the middle frame structure are in a vertical position(right)

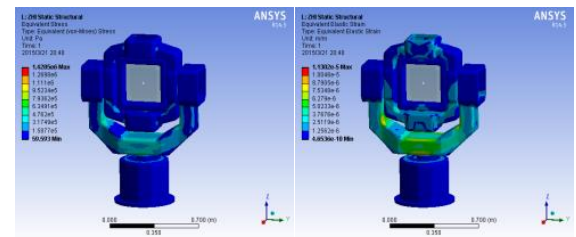

Fig 7 stress and strain of the inner frame structure and the middle frame structure in the vertical position

Fig 8 and Fig 9 respectively for the inner and middle frame structure in the horizontal position, the overall deformation result of equivalent stress and equivalent strain analysis of static force. 


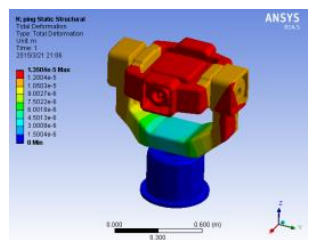

Figure 8 inner frame structure and the middle frame structure in the horizontal position of the static deformation (left)

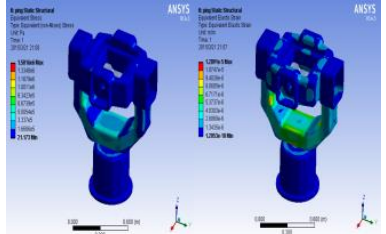

Figure 9 static stress and strain when the inner frame structure and the middle frame structure are in a horizontal position(right)

Fig10 and Fig11 respectively for the inner and middle frame structure in arbitrary position of the whole deformation, equivalent stress and equivalent strain of the static force result analysis. It can be seen from the figure that the maximum deformation occurs in the motor mounting position of the outer frame structure. The fixed position of the motor in the middle frame structure also has a certain deformation.

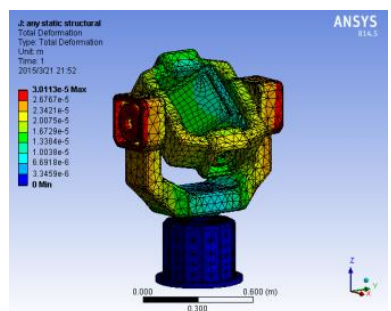

Fig10 the inner frame static deformation at arbitrary position in the structure and frame structure(left)

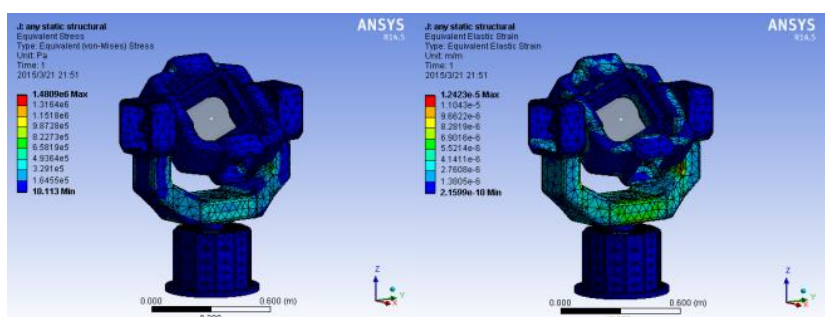

Fig11 static stress and strain of the inner frame structure and the middle frame structure at arbitrary position(right)

Through the static simulator analysis, the main deformed part of the simulation turntable obtained at static state is the outer ring structure and the maximum deformation is outer frame for motor installation.And the inflexion point of the outer frame structure may be subjected to greater stress and strain due to stress concentration. So we can eliminate stress concentration in this place by rounding. In addition to the three largest deformation of different states of simulator in the inner structure and outer ring structure are ten micron. Its absolute deformation is not large, it is acceptable.

\subsection{Analysis of structural dynamics}

Based on the finite element modeling of the simulation turntable, the application of AWB simulator and the overall frame structure of three axis of modal analysis, the modal frequencies of 1-6 orders(Table 3)and the modal deformation were obtained. At the same time, we calculated the overall modal analysis results of simulator (Fig12,13,14) and listed the three axis of the frame are the modal 1 order, 4 order, 5 order and 6 order modal sequence diagrams (Fig15,16,17,18). It can be seen from the figure(Fig19,20) that when the resonant frequency of the simulation turntable is $157.5 \mathrm{~Hz}$ under the harmonic load condition, the harmonic amplitude is the largest at $1.54 \mathrm{E}-02 \mathrm{~m}$.

Table 3 simulates turntable 1-6 modal frequencies

\begin{tabular}{l|cccc}
\hline \multirow{2}{*}{ modality } & \multicolumn{4}{|c}{ The frequency [Hz] } \\
\cline { 2 - 5 } order number & $\begin{array}{c}\text { Inner frame } \\
\text { structure }\end{array}$ & $\begin{array}{c}\text { middle frame } \\
\text { structure }\end{array}$ & $\begin{array}{c}\text { outer frame } \\
\text { structure }\end{array}$ & $\begin{array}{c}\text { The whole } \\
\text { simulation } \\
\text { turntable }\end{array}$ \\
\hline 1 & 315.95 & 231.74 & 108.08 & 91.02 \\
2 & 519.66 & 337.74 & 146.35 & 128.32 \\
3 & 815.04 & 438.44 & 146.5 & 130.08 \\
4 & 828.27 & 526.79 & 193.22 & 180.02 \\
5 & 930.88 & 654.47 & 359.71 & 332.12 \\
6 & 1324 & 837.61 & 443.33 & 420.58 \\
\hline
\end{tabular}




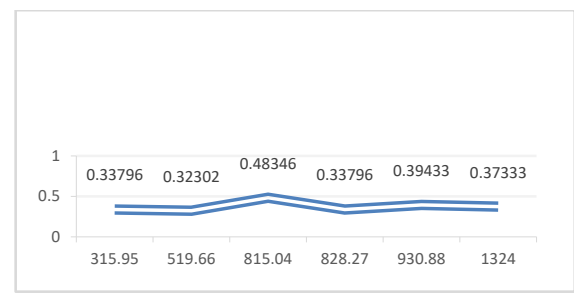

Fig 12 outer ring structure 1-6 modal frequency(left )

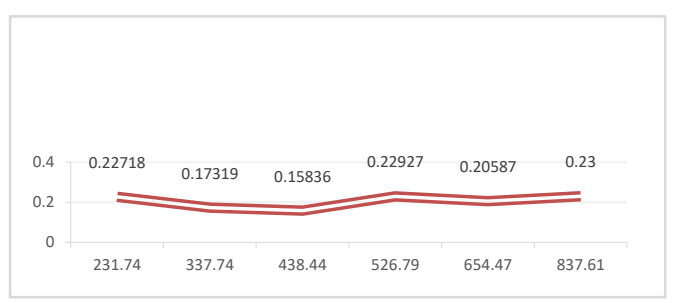

Fig 13 middle ring structure 1-6 mode frequency(right)

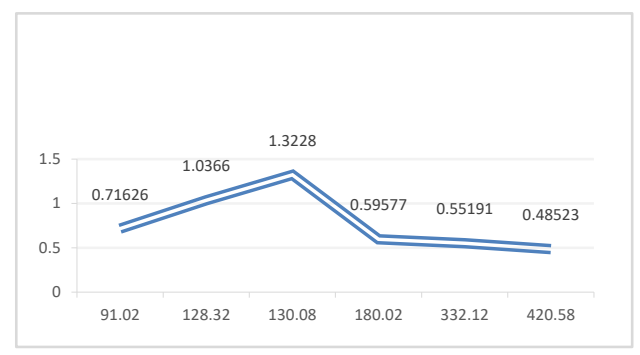

Figure 14 simulation turntable overall 1-6 order mode frequency

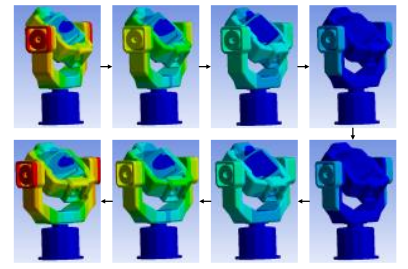

Fig 15 simulation turntable overall 1 order modal timing diagram(left)

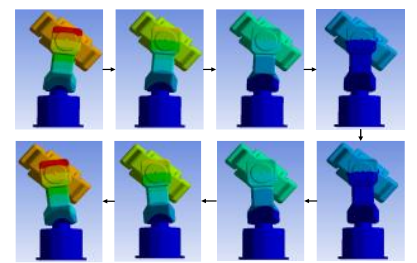

Fig 17 simulation turntable overall 5 modal timing diagram(left)

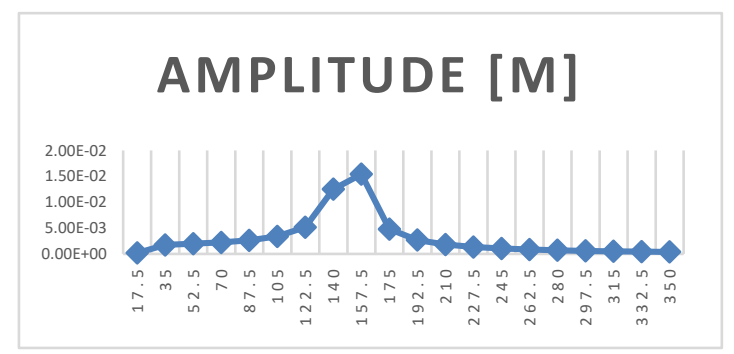

Fig19 harmonic response curve

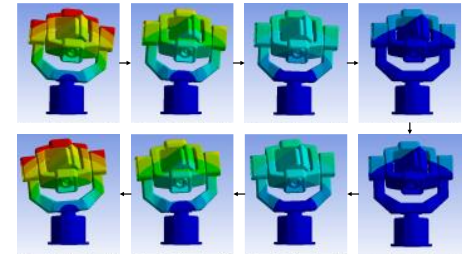

Figure 16 simulation turntable overall 4 order modal timing diagram(right)

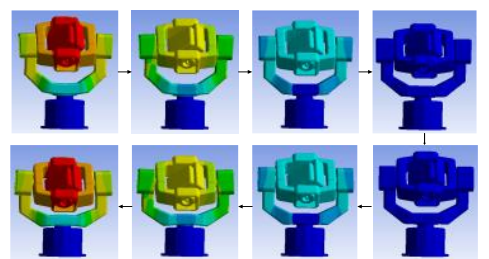

Fig 18 simulation turntable overall 6 order modal timing diagram(right)

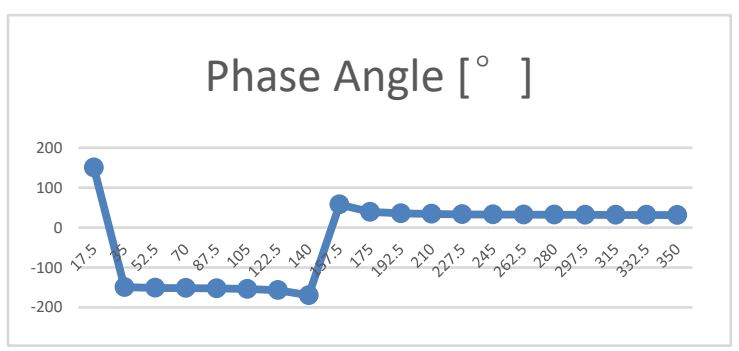

Fig 20 angle curve

\section{Conclusion}

(1) After studying the design index of the simulation turntable, this chapter established the overall design scheme of the simulation turntable. In this paper, a vertical three-axis simulation turntable directly driven by a DC torque motor. The load is fixed in the center of the inner ring structure.

(2) According to the established overall program to select the material of each part of the simulation turntable structure.For the simulation of turret inner ring structure, the middle ring structure and the outer ring structure of the frame part of use of ZL101 cast aluminum alloy, their axis 
use of 45 \# carbon steel, The base part use of HT300 gray cast iron.

(3) Through the static simulator analysis, the main deformed part of the simulation turntable obtained at static state is the outer ring structure and the maximum deformation is outer frame for motor installation.In addition to the three largest deformation of different states of simulator in the inner structure and outer ring structure are ten micron. Its absolute deformation is not large, it is acceptable.

(4) It can be seen from the figure(Fig22,23) that when the resonant frequency of the simulation turntable is $157.5 \mathrm{~Hz}$ under the harmonic load condition, the harmonic amplitude is the largest at $1.54 \mathrm{E}-02 \mathrm{~m}$

\section{References}

[1] Feng S, Bo X. A FOG Online Calibration Research Based on High-Precision ThreeaxisTurntable[C]. Proceedings of the 2009 International Asia Conference on Informatics in Control,Automation and Robotics. IEEE Computer Society, 2009:454-458.

[2] Jia-Yi Q I, Ren S Q, Wang C H. Angular Velocity Test Plan Design for Identifying the Error Model Coefficients of Gyro Using Three-Axis Turntable[J]. Journal of Astronautics, 2006,27(3):565-570.

[3] Buford Jr J A, Murrer Jr R L. Technologies for Synthetic Environments: Hardware-in-the-Loop Testing XIV[C]. Society of Photo-Optical Instrumentation Engineers (SPIE)Conference Series. 2009, 7301.

[4] $\mathrm{Wu}$ Zhouli. Research on magneto-magnetic three-axis turntable [D]. Wuhan: Huazhong University of Science and Technology, 2007.

[5] Zhou Changyi. Three-axis flight simulation control system design and control algorithm [D]. Chinese Academy of Sciences Graduate School

(Changchun Institute of Optics, Fine Mechanics and Physics), 2005.

[6] Li Qiuhong. Three-axis turntable finite element analysis [D]. Harbin Engineering University, 2007.

[7] Hauser R, Swamp M, Havlicsek H. Modern design of far-field target motion simulators[C].Defense and Security Symposium. International Society for Optics and Photonics, 2006:620805-620805-10.

[8] DeMore L A, Hollinger P, Hirsh G. Making flight motion tables invisible[C]. SPIE Defense, Security, and Sensing. International Society for Optics and Photonics, 2009: 730103-730103-19.

[9] L. D. Z. E. M. Ping. Static Performance Analysis of Aerostatic Bearing with Marc[J].Lubrication Engineering, 2005, 5(017). 